\title{
Otimização do Processo de Estampagem de Peça Automotiva Utilizando Rede Neural Artificial e Algoritmo Evolutivo Multiobjetivo
}

\author{
Peter Laureano Brendel \\ Universidade do Estado de Santa Catarina - UDESC \\ Programa de Pós-Graduação em Computação Aplicada \\ Joinville - Brasil \\ peter.brende197@gmail.com \\ Fabiano Miranda \\ ArcelorMittal \\ Global R\&D Group \\ São Franciso do Sul - Brasil \\ fmiranda.fabiano@gmail.com
}

\author{
José Osvaldo Amaral Tepedino \\ ArcelorMittal \\ Global R\&D Group \\ São Franciso do Sul - Brasil \\ jose.tepedino@arcelormittal.com.br
}

\author{
José Francisco Silva Filho \\ ArcelorMittal \\ Global R\&D Group \\ São Franciso do Sul - Brasil \\ jose.francisco@arcelormittal.com.br
}

\author{
Rafael Stubs Parpinelli \\ Universidade do Estado de Santa Catarina - UDESC \\ Programa de Pós-Graduação em Computação Aplicada \\ Joinville - Brasil \\ rafael.parpinelli@udesc.br
}

\begin{abstract}
A estampagem de peça automotiva é o processo de criar algumas partes metálicas que são utilizadas para compor a estrutura de automóveis como, por exemplo, o capô de um carro. $O$ problema se caracteriza como problema de otimização multiobjetivo porque é possível encontrar uma combinação de variáveis que impactam diferentes critérios de produção. No presente trabalho é apresentado um modelo neuro-evolutivo para identificar valores otimizados de variáveis desse processo, de modo a atender simultaneamente três objetivos, fratura, ruga e estiramento insuficiente, para a fabricação sem falhas. $O$ modelo de RNA é construído utilizando dados de simulações numéricas do processo de estampagem e este modelo é utilizado pelo algoritmo NSGA-II para vasculhar o espaço de busca considerando os múltiplos objetivos. Resultados obtidos pela abordagem proposta demonstram a eficiência do modelo, contribuindo para identificação de uma solução mais eficiente para o estudo de caso experimentado.
\end{abstract}

Index Terms-Otimização multiobjetivo, Estampagem Metálica, Redes Neurais Artificiais, Computação Evolucionária, Indústria Automotiva

\section{INTRODUÇÃO}

A operação de conformação por estampagem é um processo mecânico complexo, largamente utilizado na indústria automobilística onde se necessita alta produção, baixo índice de sucatamento e rigor de dimensões [1]. O processo consiste na utilização de uma matriz, de um prensa-chapas para prender a chapa e de um punção que faz com que a chapa penetre na matriz, dando a forma adequada à peça final. O desafio é formar uma peça sem falhas, evitando a ocorrência de defeitos como fratura, ruga e Estiramento Insuficiente (EI). Cada uma destas falhas ocorrem por motivos distintos, porém as contramedidas processuais normalmente utilizadas para evitar ou minimizar o surgimento de um deles podem implicar no aumento da intensidade ou risco de surgir o outro. A fratura, por exemplo, ocorre quando durante a operação de estampagem uma região é submetida a uma quantidade excessiva de deformações, não suportado pela chapa. O EI é justamente o contrário, ou seja, quando há pouca deformação sobre uma região da peça conformada, que normalmente leva a uma falta de rigidez local, que pode inviabilizar o uso em painéis expostos, por exemplo [2]. O desenvolvimento de deformações excessivamente compressivas, que levam a formação de rugas, são normalmente inaceitáveis em peças com requisitos estéticos. Portanto, a minimização, ou eliminação completa, destes três problemas é essencial para garantir bons rendimentos produtivos no processo de estampagem, bem como a adequação aos padrões estruturais e estéticos necessários para utilização da peça nos veículos.

Atualmente, os profissionais que atuam no desenvolvimento de peças e ferramentas de estampagem utilizam seus conhecimentos para configurar um conjunto amplo de parâmetros, cuja combinação ótima para minimizar as falhas é muito baseada na experiência e em etapas de tentativa-e-erro. $\mathrm{O}$ grande problema deste método é tornar o processo tendencioso e possivelmente passar próximo à uma configuração melhor, mas que está fora da visão do desenvolvedor e das suas experiências. Por esse motivo, permanecer em estado empírico pode atrasar o desenvolvimento, bem como ampliar o risco de ocorrência de 
problemas ao longo do processo produtivo [3].

O problema abordado neste artigo é a otimização multiobjetivo da estampagem do teto de um veículo. Para detalhar, é preciso encontrar um conjunto de parâmetros que, quando aplicados na simulação de estampagem da peça, minimizem as ocorrências de fratura, enrugamento e EI. Como citado anteriormente, estes objetivos são divergentes, e o principal desafio é zerar a fratura e minimizar os demais objetivos.

No presente trabalho, é apresentado um modelo neuroevolutivo que combina Rede Neural Artificial (RNA) e o algoritmo evolutivo multiobjetivo Nondominated sorting genetic algorithm II (NSGA-II), para identificar valores otimizados de variáveis desse processo, de modo a atender simultaneamente os diferentes critérios necessários para a fabricação sem falhas. O modelo de RNA é construído utilizando dados de simulações numéricas do processo de estampagem e este modelo é utilizado pelo NSGA-II para vasculhar o espaço de valores das variáveis.

A ferramenta utilizada para coletar os dados das simulações numéricas é o AutoForm (www.autoform.com) por ser a ferramenta empregada pela empresa parceira no desenvolvimento. A partir dele foi possível configurar e executar um conjunto de experimentos, selecionar algumas variáveis de interesse dos parâmetros da simulação e definir seus domínios. Desta forma, há a possibilidade de extrair uma base de dados diversificada, onde cada linha é formada pelas variáveis de um experimento e seus resultados. Essa base permite criar uma RNA com treinamento supervisionado, visto que temos os pares de entrada e saída para validação. Além disso, como todas as variáveis são de domínio contínuo, o problema abordado se caracteriza em uma regressão com múltiplas saídas, sendo elas as áreas relativas das três resultantes de cada experimento: fratura, enrugamento e EI.

Este trabalho está organizado da seguinte maneira. A Seção I fundamenta os conceitos envolvidos no desenvolvimento da proposta. Na seção III] há a descrição de alguns trabalhos correlatos. O modelo proposto para resolução do problema é detalhado na seção IV. Em seguida, a seção V apresenta o estudo de caso e as tecnologias utilizadas e, por fim, a seção VI traz as conclusões obtidas e as possibilidades de trabalhos futuros.

\section{FUNDAMENTAÇÃO}

Esta seção descreve os principais conceitos necessários para o melhor entendimento deste trabalho

\section{A. Estampagem de Peça Automotiva}

A estampagem é uma das etapas mais importantes no processo de desenvolvimento de peças automotivas porque está diretamente relacionada com a qualidade do produto [1]. A otimização de estampagem é desafiadora, porque é obtida através da seleção de valores para diversos parâmetros e fornece no final um balanço entre ductibilidade e resistência mecânica, que são características antagônicas. Em etapa de simulação numérica, a metodologia de seleção dos valores das variáveis do processo é normalmente baseada em avaliações empíricas. Essa metodologia é, por vezes, limitada e imprecisa. Segundo Tekkaya [3], a indústria automobilística quer, cada vez mais, reduzir o peso dos veículos e isso torna necessário alterar os meios de produção, tornando-o mais robusto para os desafios técnicos que se apresentam.

No trabalho de Wei, Yang e Xing [4], o gráfico representado pela Figura 11 foi apresentado. Nele, existem três curvas, baseada nas menores e maiores deformações (eixos $\mathrm{x}$ e $\mathrm{y}$, respectivamente) desenvolvidas ao longo da superfície da peça estampada. Cada curva representa um limiar para ocorrência de: fratura $(\phi)$, chamada de Curva Limite de Conformação (CLC); enrugamento $(\psi)$, Curva Limite de Ruga; e de EI $(\bar{\varepsilon})$, Curva de Estiramento Insuficiente. Cada ponto é posicionado conforme a mínima e máxima deformação de alguma região da peça, respectivamente os eixos $E_{1}$ e $E_{2}$ do gráfico. Para um ponto neste espaço ser considerado ótimo, ele deve atender as seguintes condições:

1) Estar abaixo da curva de fratura $(\phi)$;

2) Estar à direita do limite de ruga $(\psi)$;

3) Estar fora da semicircunferência de EI $(\bar{\varepsilon})$.

Essa análise proporciona a visualização do conflito para minimização de todos os objetivos. Para exemplificar, à medida que, em uma configuração de simulação, a proporção de EI diminui, é possível que haja aumento de enrugamento ou ruptura.

Fig. 1. Definição dos objetivos

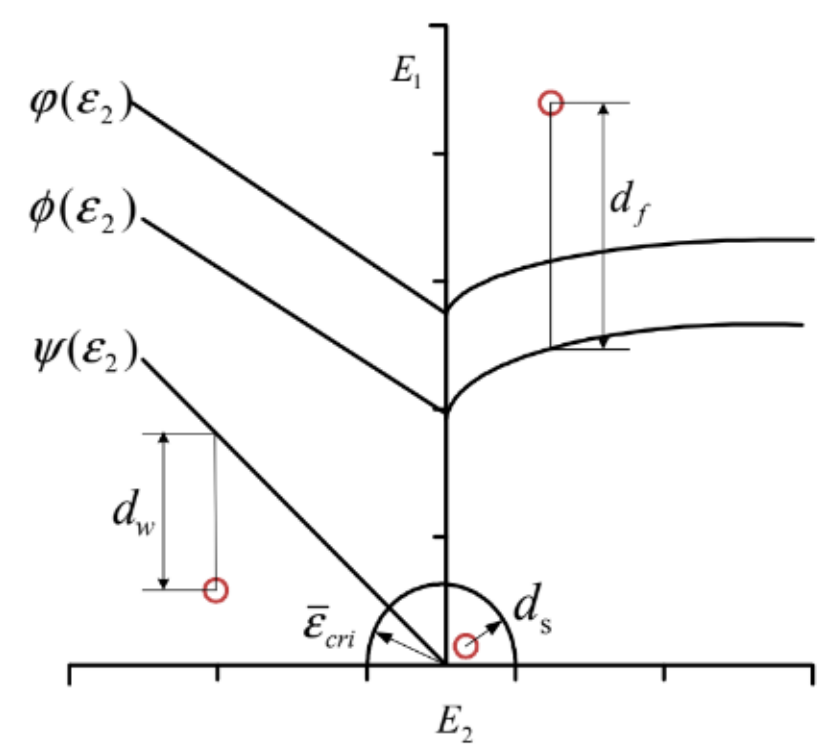

Fonte: Adaptado de Wei, Yang e Xing [4]

\section{B. Otimização Multiobjetivo e Algoritmo NSGA-II}

No mundo real, é comum encontrar problemas complexos que requerem uma combinação de variáveis, geralmente limitadas por um domínio, a fim de maximizar ou minimizar, simultaneamente, um determinado número de funções objetivo concorrentes [5]. Estas características definem os problemas multiobjetivo. Outra característica importante, destacada no 
trabalho de Deb et al. [6] é que, diferente dos problemas de único objetivo, é possível que não exista uma solução que é globalmente ótima para todos os objetivos, mas sim, um conjunto de soluções que são dominantes (melhores) em algum objetivo, mas dominadas (piores) em outros. Esse tipo de solução foi definido formalmente como conjunto de ótimos de Pareto [6], [7].

$\mathrm{Na}$ literatura existem diversos algoritmos evolutivos para otimização multiobjetivo, tendo o algoritmo NSGA-II como um dos mais utilizados [6]. Algumas características destacam este algoritmo, sendo uma delas a ordenação não dominada das soluções a cada geração, cujo objetivo é dividir as soluções encontradas em fronteiras hierárquicas. Outra característica é a seleção dos melhores indivíduos no processo evolutivo, baseado no ranqueamento das fronteiras. Uma outra característica importante é a ordenação por distância de aglomeração. Ela é responsável por criar critérios de seleção de indivíduos quando não é possível selecionar um nível hierárquico inteiro. A ordenação baseia-se na distância do indivíduo de todos os outros e a prioridade se dá para os indivíduos que estão mais afastados entre si, promovendo uma maior diversificação.

\section{Aprendizado Supervisionado e Redes Neurais Artificiais}

O aprendizado supervisionado [8] é um dos paradigmas para aprendizado de máquina definido pela atuação de uma supervisão, que fornece as saídas esperadas para um conjunto de entrada, o que permite realizar cálculos e adaptações para o erro da resposta fornecida pelo modelo sendo gerado.

A regressão [9] é uma técnica estatística utilizada para encontrar relações entre dados quantitativos de entrada e saída. Essas relações são funções que, quando aplicadas em algum ponto desconhecido, sugerem um possível resultado seguindo a tendência dos dados conhecidos. Para complementar, quando é preciso encontrar relação entre um conjunto de entrada e um conjunto de vetores de saídas, tem-se uma regressão de múltiplas saídas.

As RNAs [10] são inspiradas na maneira em que o cérebro humano processa informações. Elas são definidas por uma coleção de camadas compostas por nós que podem ser de entrada, saída ou intermediários - também conhecidos como escondidos - além de pesos que são ajustados na fase de treinamento da rede. No caso das RNAs, a aprendizagem é determinada com base na modificação dos pesos dos nós da rede levando em consideração o erro gerado por uma resposta. Neste trabalho, o objetivo é utilizar uma RNA como modelo de regressão dos dados, através do aprendizado supervisionado, que fornecerá ao algoritmo evolutivo um modelo para vasculhar o espaço de busca do problema.

\section{Trabalhos Relacionados}

Na literatura, existem diversos trabalhos cujo foco é otimizar o processo de estampagem ou algum processo mecânico relacionado. Com o passar dos anos a abordagem computacional, através de algoritmos evolutivos, cresceu muito e tornou-se um método confiável capaz de gerar bons resultados.
O trabalho de Wei, Yang e Xing [4], realiza a otimização multiobjetivo de peças automotivas através de algoritmos genéticos. O algoritmo aplicado pelo autor para resolver o problema foi o Multi-Objective Genetic Algorithm (MOGA). Neste artigo, as funções objetivo que são otimizadas ditam, diretamente, o comportamento de fratura, enrugamento e estiramento insuficiente de uma peça. Concluiu-se que o uso de Algoritmo Evolutivo (AE)s no processo de estampagem é viável e facilita o ciclo de produção, visto que diminui o processo de tentativa e erro no momento de seleção das variáveis. Embora o trabalho tenha semelhanças ao proposto, não é válido realizar uma comparação direta entre os resultados dos métodos, uma vez que a diferença entre as peças pode tendenciar as possíveis análises. A principal diferença, além dos dados, está na metodologia adotada para resolver o problema, os autores utilizam simulação numérica acoplada ao ciclo evolutivo, e nossa proposta visa tornar estas etapas independentes, através de uma RNA.

Oujebbour et al. [11] busca otimizar a forma inicial da chapa de metal, de modo a reduzir o risco de falhas e o retorno elástico. No processo de estampagem estes dois objetivos são conflitantes, o que significa que são problemas complexos de otimizar. Aqui, os autores utilizaram o simulador LS-DYNA para realizar as simulações com o Método de Elementos Finitos (FEM) combinado com os algoritmos NSGA-II, Normal Boundary Intersection (NBI) e Normalized Normal Constraints Methods (NNCM) para realizar a otimização multiobjetivo e compará-los. A simetria da peça facilita a modelagem, permitindo que apenas $1 / 4$ da peça seja necessária para realizar os experimentos. Vale notar que o processo de otimização não utiliza funções que descrevem os objetivos diretamente, mas sim, aproximações geradas através do método Sparse Grid Interpolation (Interpolação de Grade Esparsa). Os experimentos apresentados mostram vantagens do NSGA-II considerando a distribuição das soluções. Contudo, a interpretação dos autores é que os outros dois modelos são capazes, neste problema, de atingir resultados bons com menor número de computações.

No trabalho de Zerti et al. [12] um dos objetivos é investigar a influência de diferentes parâmetros no processo de torneamento de um aço inoxidável específico. A modelagem do sistema segue um planejamento de experimentos de Taguchi $\mathrm{L}_{25}$. Outro objetivo, era investigar o uso de redes neurais artificiais para a modelagem das equações que representam os objetivos a ser otimizados. Os autores utilizaram a metodologia de Response Surface Methodology (RSM) como alternativa e concluíram que a rede neural artificial modelada era capaz de aproximar com maior precisão os objetivos. Segundo eles, a correlação dos coeficientes aumentou consideravelmente, em um dos casos de 87.31 para $99.99 \%$. Um lado ruim de utilizar as redes neurais é não conseguir quantificar a influência de cada um dos parâmetros, o que é possível através do RSM.

\section{Modelo Proposto}

Esta seção detalha o modelo neuro-evolutivo para o problema de estampagem de peça automotiva. O modelo de RNA 
é construído utilizando dados de simulações numéricas do processo de estampagem e este modelo é utilizado pelo algoritmo NSGA-II para vasculhar o espaço de valores das variáveis. O software de simulação AutoForm foi utilizado para coleta de dados experimentais. A Figura 2 apresenta uma visualização do modelo proposto e cada etapa é detalhada a seguir.

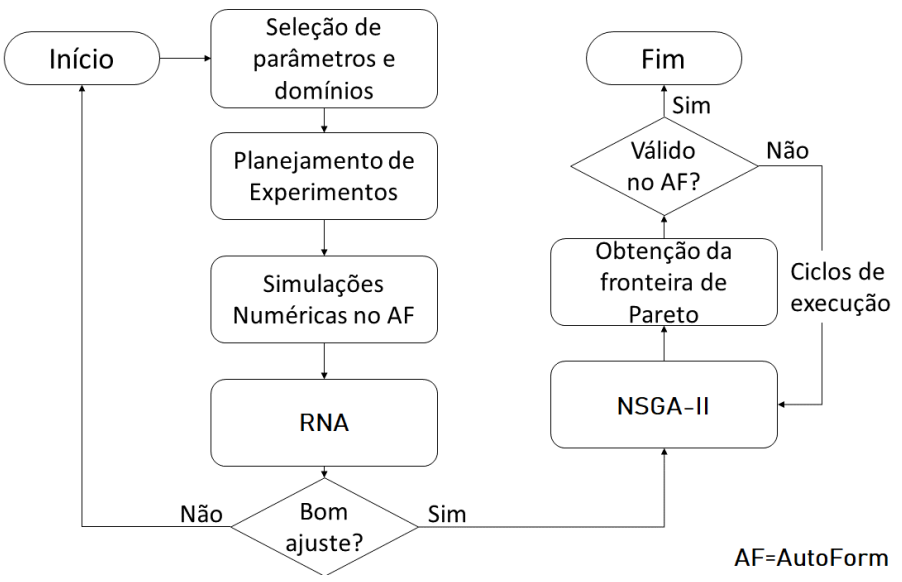

Fig. 2. Modelo neuro-evolutivo proposto para otimização do processo de estampagem automotiva

O processo se inicia na seleção de parâmetros e domínios. Esta etapa é importante para definição da matriz de experimentos do AutoForm. Para as RNAs, o ideal é criar um plano com uma vasta gama de experimentos a fim de cobrir ao máximo o espaço de busca e facilitar a regressão dos dados. O objetivo é que se tenha diversidade nos resultados de simulação numérica. Alguns exemplos de parâmetros possíveis são:

- Carga de Prensa-Chapa (CPC): A força exercida que controla o fluxo da chapa para o interior da matriz durante o processo de estampagem.

- Coeficiente de Atrito (CDA): Coeficiente de atrito do sistema chapa/ferramenta. Está relacionado à resistência da chapa em deslizar sobre o ferramental.

- Força de Drawbead (FDB)s: Forças empregadas no drawbead. Frisos utilizados para controlar o fluxo da chapa.

- Comprimento do Blank (CB) e Largura do Blank (LB): As dimensões de comprimento e largura da chapa (blank), respectivamente.

Para aplicação das RNAs com aprendizado supervisionado é preciso coletar dois conjuntos de dados para criação de uma base. $\mathrm{O}$ primeiro conjunto, representando as variáveis independentes, detalha as configurações de cada experimento. Estes dados são gerados automaticamente pelo AutoForm. O segundo, representando as variáveis dependentes, detalha o conjunto de resultados de cada experimento. Neste, o interesse está na área de cada objetivo, proporcional à área total da peça após a simulação de estampagem no AutoForm. Até a presente versão do modelo, a extração das áreas é feita de maneira manual, por experimento. A partir da definição de um domínio para cada variável, é feita uma combinação, pelo AutoForm, que forneça balanço na quantidade de dados para cada objetivo. Importante notar que os dados são de domínios muito variados e, por este motivo, devem ser normalizados em uma rotina de pré-processamento.

$\mathrm{Na}$ etapa de regressão, para criar o modelo de RNA foi preciso atenção no tratamento dos dados e implementar uma lógica para modelar a rede, definir as camadas de entrada e saída de acordo com os dados disponíveis. A definição da arquitetura foi feita de maneira empírica. Pré-processamento de dados com rotinas de uniformização dos domínios para entrada no modelo da RNA foram aplicados. A base de dados é dividida de maneira aleatória em três porções de dados, sendo treino, validação e teste.

O último passo do modelo é estruturar o NSGA-II, as características de um indivíduo são utilizadas para consultar a RNA, que funciona como a função de fitness. Considerando as saídas do algoritmo genético, é esperado que a partir dos resultados obtidos seja possível refletir a otimização no Autoform. Para verificar que isso ocorre é necessário selecionar um dos indivíduos gerados como saída, analisar seu cromossomo e parametrizar um novo experimento no simulador com as características deste indivíduo. Caso a validação não seja satisfatória é preciso reavaliar a parametrização do Algoritmo Genético (AG). Para facilitar a configuração, é possível utilizar alguns gráficos de convergência, de diversidade fenotípica, da fronteira de Pareto, que auxiliam na detecção de falhas no processo evolutivo.

\section{ExPerimentos, Resultados e AnÁlises}

O estudo de caso deste trabalho se aplica a uma peça automotiva do teto de um veículo, uma peça lisa e com poucos detalhes. No primeiro momento não foram feitos experimentos com outras variáveis, optou-se por selecionar apenas as mais influentes do sistema que foram definidas por informações de alto nível do especialista. A tabela I] apresenta as variáveis e os respectivos domínios para este estudo de caso.

\begin{tabular}{|c|c|c|c|}
\hline & Mínimo & Médio & Máximo \\
\hline CPC & 1200 & 1500 & 1800 \\
\hline FDB3 & 0.126 & 0.189 & 0.252 \\
\hline CDA & 0.14 & 0.15 & 0.16 \\
\hline \multicolumn{4}{|c|}{ TABLE I } \\
\hline
\end{tabular}

TABELA DE DOMÍNIOS. O PONTO MÉDIO É UTILIZADO APENAS NO PLANEJAMENTO DE EXPERIMENTOS

A RNA foi desenvolvida em Python com auxílio da biblioteca Keras ${ }^{1}$ e a arquitetura foi definida de maneira empírica. A arquitetura aplicada neste este estudo é do tipo 3-6-6-3, ou seja, três neurônios na camada de entrada representando as variáveis independentes do problema (CPC, FDB3 e CDA), seguida de duas camadas ocultas com seis neurônios cada uma e três neurônios na camada de saída representando as variáveis dependentes do problema (valores dos objetivos sendo otimizados na estampagem). As camadas ocultas utilizam função de ativação retificadora (rectifier).

\footnotetext{
${ }^{1}$ Keras: https://keras.io/
} 
O aprendizado supervisionado ocorre ao longo de 1000 épocas e a base de dados é composta da extração dos 200 experimentos, onde cada entrada correlaciona a parametrização do AutoForm com as falhas (fratura, ruga e EI) ocorridas após a simulação. A divisão desta base foi dada da seguinte maneira: $70 \%$ dos dados para treinamento, $15 \%$ para validação e $15 \%$ para teste.

A biblioteca pymoo [13] foi utilizada para aplicação do algoritmo NSGA-II, que executou 30 vezes para obtenção de média e desvio padrão. A implementação das funções objetivo e parametrização foram as etapas necessárias para iniciar o processo evolutivo. Foi aplicado um total de 1000 gerações com uma população de 100 indivíduos com codificação real. Os operadores de crossover e mutação selecionados foram o Simulated Binary Corssover (SBX) com probabilidade de $90 \%$ e mutação polinomial com $5 \%$ de chance de ocorrer. Todas as execuções do AutoForm acontecem em arquitetura com processador i7-8750H @ 2.20GHz. Enquanto isso, o algoritmo evolutivo e a rede neural artificial executam em processador i5-9600k @ 3.7GHz. Os parágrafos que seguem fazem análise dos resultados obtidos em cada etapa do experimento.

A figura 3 apresenta a curva de perda por época e indica a convergência da RNA. Esta curva mostra boa qualidade dos dados visto que a função de perda já inicia baixa, atingindo $99 \%$ de acurácia e 0.013 de perda. Nota-se ainda que a curva de treino está um pouco acima comparada à de validação, isso ocorre porque o conjunto é pequeno e bem distribuído, facilitando a qualidade dos acertos ao validar.

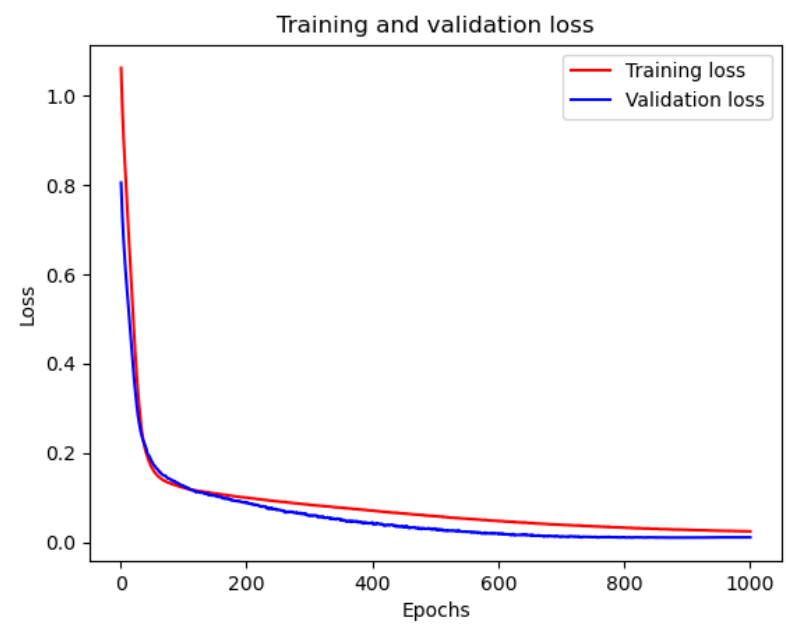

Fig. 3. Gráfico de convergência Perda x Épocas

A tabela [I] apresenta a média e desvio padrão das médias de cada objetivo para cada execução. Por esta tabela pode-se analisar que as diversidades estão concentradas nas execuções individuais do algoritmo. Além disto, ao analisar o desvio padrão de todos os objetivos pode-se concluir que o NSGA-II é capaz de retornar fronteiras de Pareto consistentes em todas as execuções.

\begin{tabular}{|l|l|l|l|}
\hline & Fratura & Enrugamento & EI \\
\hline Média & 0.00744 & 4.38394 & 82.84384 \\
\hline Desvio Padrão & 0.00042 & 0.04327 & 0.05900 \\
\hline
\end{tabular}

MÉdia E DESVIO PADRÃo DE FRATURA, RUGA E EI POR EXECUÇÃo (30 EXECUÇÕES)

Sabendo que o NSGA-II fornece fronteiras consistentes e diversificadas é possível selecionar indivíduos de uma única execução para fazer a análise dos resultados. Estes indivíduos foram utilizados para validação no AutoForm e foi notável a relação direta entre os resultados encontrados e a saída do processo de estampagem. A figura 4 mostra a fronteira de Pareto obtida de uma execução do NSGA-II e destaca o indivíduo selecionado pelo especialista. Nota-se que as soluções ótimas estão agrupadas de maneira visível, o que indica que, para este cenário, o impacto de cada variável nos objetivos estava bem definido através da RNA.

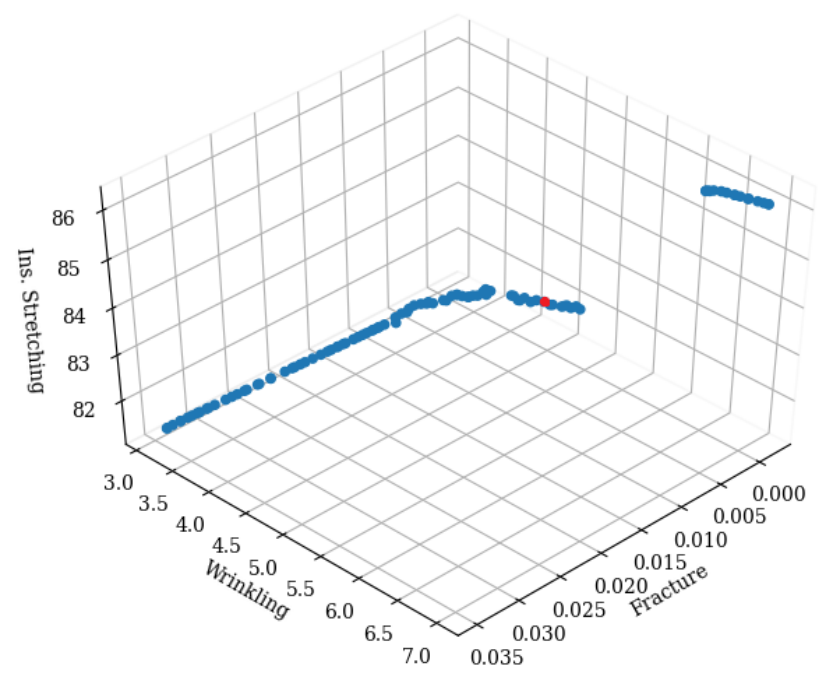

Fig. 4. Fronteira de Pareto com destaque em vermelho para o indivíduo selecionado pelo especialista.

A figura 5 apresenta a simulação da estampagem obtida pela configuração empírica definida pelos especialistas da empresa e compara com a simulação obtida pela configuração obtida pelo modelo proposto. Em conjunto, a tabela III apresenta a configuração de variáveis e resultados dos objetivos obtidos pela estampagem original da peça obtida de maneira empírica pelos especialistas da empresa e compara com a configuração obtida pela abordagem proposta. O resultado obtido pelo modelo proposto fornece uma peça livre de fraturas e reduz em quase a metade o enrugamento inicial, diminuindo em $5 \%$ a região de estiramento. Em outras palavras, o resultado obtido pelo modelo traz uma melhora significativa não apenas para a conformação da peça, mas também para o custo de desenvolvimento dela. 
(a) Estampagem original

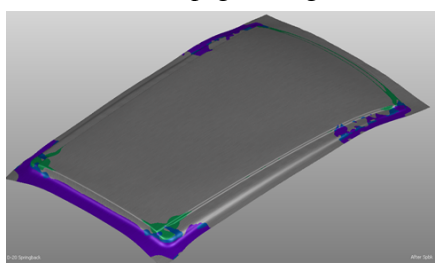

(b) Estampagem sugerida pelo $\mathrm{AE}$

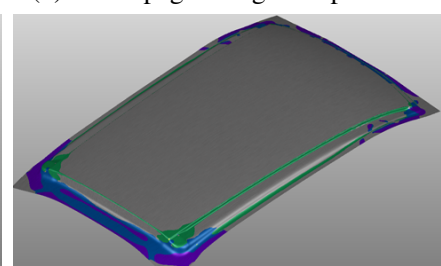

Fig. 5. Comparação das condições de estampagem da peça estudada, percebese a redução da área cinza (EI) e roxa (enrugamento).

\begin{tabular}{|c|c|c|c|c|c|c|}
\hline & CPC & FDB3 & CDA & Fratura & Enrugamento & EI \\
\hline Empírico & 2300 & 0.450 & 0.15 & 0.00 & 8.10 & 87.31 \\
\hline Otimizado & 1200 & 0.244 & 0.14 & 0.00 & 4.84 & 82.43 \\
\hline
\end{tabular}

TABLE III

DIFERENÇA DA PROPORÇÃO DE ÁREA AFETADA, EM PORCENTAGEM, POR OBJETIVO

\section{Conclus Ão e trabalhos Futuros}

A conformação de uma chapa de aço por estampagem é um processo mecânico complexo, largamente utilizado na indústria automobilística onde se necessita de alta produção, baixo índice de sucatamento e rigor de dimensões [1]. O desafio é formar uma peça sem falhas, evitando a ocorrência de defeitos como fraturas, rugas e estiramento insuficiente. Atualmente, os profissionais que atuam no desenvolvimento de peças e ferramentas de estampagem utilizam seus conhecimentos para configurar um conjunto amplo de parâmetros, cuja combinação ótima para minimizar as falhas é muito baseada na experiência e em etapas de tentativa-e-erro. Por esse motivo, permanecer em estado empírico pode atrasar o desenvolvimento, bem como ampliar o risco de ocorrência de problemas ao longo do processo produtivo.

No presente trabalho, é apresentado um modelo neuroevolutivo que combina RNA e o algoritmo evolutivo multiobjetivo NSGA-II, para identificar valores otimizados de variáveis do processo de estampagem, de modo a atender simultaneamente os critérios de fratura, enrugamento e EI. O modelo de RNA é construído utilizando dados de simulações numéricas do processo de estampagem e este modelo é utilizado pelo NSGA-II para vasculhar o espaço de valores das variáveis.

Um estudo de caso do teto de um automóvel foi aplicado utilizando a abordagem proposta e os resultados obtidos foram bastante encorajadores para aplicação em outros estudos de caso. Percebe-se que o algoritmo é capaz de encontrar fronteiras de Pareto diversificadas para o problema.

Ao optar por dados brutos do AutoForm, coletados de maneira manual, foi possível obter resultados muito interessantes combinando a RNA e o NSGA-II, que permitiram otimizar a estampagem da peça estudada e melhorar as condições originais obtidas de maneira empírica pelos especialistas da empresa.

Para este trabalho, coletar os valores de área de maneira manual foi bom para validar o conceito, visto que estes dados foram uma ótima fonte de abstração para todo o sistema de otimização. Como trabalho futuro, pretende-se desenvolver uma rotina para automatizar a coleta dos dados objetivando reduzir tempo, trabalho e risco de erros. Além disso, como outro direcionamento futuro, pretende-se verificar como o sistema se comporta caso hajam menos ou mais variáveis para a otimização, com o objetivo de reduzir ainda mais as áreas de enrugamento e estiramento insuficiente. Um grande desafio é considerar novas funções objetivo para compor o conjunto atual no processo de otimização. Também é válido estudar o impacto de outros AE no sistema e buscar auxílio de ferramentas mais sofisticadas para modelar a RNA, como uso de estratégias de aprendizado de máquina automático (AutoML). Por fim, já estão elencados novos estudos de casos com outras peças automotivas com diferentes graus de complexidade.

\section{AGRADECIMENTOS}

Os autores agradecem a empresa ArcelorMittal VEGA pelo apoio financeiro e técnico durante o desenvolvimento do trabalho.

\section{REFERÊNCIAS}

[1] G. Ma and B. Huang, "Optimization of process parameters of stamping forming of the automotive lower floor board," Journal of Applied Mathematics, vol. 2014, p. 470320, Aug 2014.

[2] S. Holmberg and P. Thilderkvist, "Influence of material properties and stamping conditions on the stiffness and static dent resistance of automotive panels," Materials Design, vol. 23, no. 8, pp. 681-691, 2002.

[3] A. Tekkaya, "State-of-the-art of simulation of sheet metal forming," JOURNAL OF MATERIALS PROCESSING TECHNOLOGY, vol. 103, pp. 14-22, 062000.

[4] W. Liu, Y. Y. Yang, and Z. W. Xing, "Automatic process optimization of sheet metal forming with multi-objective," AIP Conference Proceedings, vol. 778, no. 1, pp. 843-848, 2005.

[5] E. Zitzler and L. Thiele, "Multiobjective optimization using evolutionary algorithms - a comparative case study," in Parallel Problem Solving from Nature - PPSN V, A. E. Eiben, T. Bäck, M. Schoenauer, and H.-P. Schwefel, Eds. Berlin, Heidelberg: Springer Berlin Heidelberg, 1998, pp. 292-301.

[6] N. Srinivas and K. Deb, "Multiobjective optimization using nondominated sorting in genetic algorithms," Evolutionary Computation, vol. 2, no. 3, pp. 221-248, 1994.

[7] V. Chankong and Y. Y. Haimes, Multiobjective decision making: theory and methodology. New York, United States: Dover Publications Inc. 1983.

[8] L. Fleck, M. H. F. Tavares, E. Eyng, A. C. Helmann, and M. A. de Moraes Andrade, "Redes neurais artificiais: Princípios básicos," Revista Eletrônica Científica Inovação e Tecnologia, vol. 1, no. 13, pp. $47-57,2016$.

[9] T. M. d. S. Rafael Izbicki, "Machine learning sob a ótica estatística," 2019.

[10] N. Gupta, "Artificial neural network," vol. 3, 2013.

[11] F.-Z. Oujebbour, A. Habbal, R. Ellaia, and Z. Zhao, "Multicriteria shape design of a sheet contour in stamping," Journal of Computational Design and Engineering, vol. 1, no. 3, pp. 187 - 193, 2014.

[12] A. Zerti, M. A. Yallese, I. Meddour, S. Belhadi, A. Haddad, and T. Mabrouki, "Modeling and multi-objective optimization for minimizing surface roughness, cutting force, and power, and maximizing productivity for tempered stainless steel aisi 420 in turning operations," The International Journal of Advanced Manufacturing Technology, vol. 102, no. 1, pp. 135-157, May 2019.

[13] J. Blank and K. Deb, "Pymoo: Multi-objective optimization in python," vol. 8. United States: IEEE, 2020, pp. 89497-89509. 